\title{
TRATAMENTO ENDODÔNTICO E CIRÚRGICO DE CISTO PERIAPICAL EXTENSO COM REMOÇÃO DE FíSTULA EXTRA-ORAL - RELATO DE CASO
}

Tatiane Camargo Wenceslau JOSLIN, Vanessa Schüssler da SILVA, Leandro Eduardo KLÜPPEL, Rosario Arruda Moura ZEDEBSKI, Rafael SARTORI

AC, feminino, 23 anos, procurou a clínica de Odontologia da UEPG buscando uma restauração do dente 42 fraturado há 7 anos. No exame radiográfico foi identificada uma lesão radiolúcida extensa na região dos incisivos inferiores, sugestivo de cavidade cística. Os tratamentos endodônticos dos dentes 32, 31, 41, 42 e 43 foram realizadas, com posterior cirurgia para a remoção da lesão e da fístula extra-oral, e realização do exame anatomopatológico. Foi feito o controle pós operatório de 15, 30 e 90 dias, demonstrando reparo aceitável. O laudo do exame microscópico reiterou a sugestão diagnóstica.

Palavras-chave: Endodontia; Cirurgia; Cisto 